\title{
AÇÕES AFIRMATIVAS NO SISTEMA EDUCACIONAL: TRAJETÓRIAS DE JOVENS NEGRAS DA UNIVERSIDADE DE BRASÍLIA
}

\author{
WIVIAN WELLER \\ Universidade de Brasília \\ MARLY SILVEIRA \\ Universidade de Brasília
}

\begin{abstract}
Resumo: O presente artigo apresenta experiências vividas por jovens universitárias que ingressaram pelo sistema de cotas na Universidade de Brasília nos cursos de Engenharia e Ciências Sociais e que apresentam distintas trajetórias de socialização escolar. Analisa as experiências vividas nesses espaços assim como as estratégias diferenciadas no que diz respeito ao enfrentamento do preconceito e da discriminação. Apresenta ainda as avaliações realizadas pelas jovens a respeito da implementação de cotas para estudantes negros nas universidades públicas. Concordamos que não adianta a medida ser justa e estar de acordo com os imperativos da justiça social se ela não produz resultados. As cotas não representam a única forma de luta por reconhecimento e redistribuição, mas refletem a importância e a necessidade de uma modificação mais profunda na gramática dos discursos no interior da universidade e no atendimento das demandas políticas e sociais.
\end{abstract}

Palavras-chave: ações afirmativas; universidade; negros e educação; juventude; gênero.

\section{Notas introdutórias: ações afirmativas no sistema educacional}

No momento de eleger pontos de apoio para direcionar o olhar sobre a situação educacional da população negra no Brasil, 120 anos após a abolição da escravatura, alguns estudos e pesquisas chamam a atenção pela renovação que estão trazendo ao debate. Sem desmerecer as inesgotáveis análises de natureza quantitativa ou fundamenta-

Copyright (c) 2008 by Revista Estudos Feministas. 
das nas teorias do capital humano e do capital cultural ou na contraposição entre o universalismo e a especificidade das estratégias de abordagem dessa complexa problemática, esses estudos avançam numa perspectiva que desvela a iniqüidade no sistema educacional, mas também apontam para a necessidade de políticas de reconhecimento, valorização cultural e afirmação de direitos dos setores historicamente excluídos dos níveis de educação mais elevados. Nessa direção destacam-se os estudos de Luiz Alberto Oliveira Gonçalves e Petronilha B. G. Silva, nos quais defendem a importância de uma perspectiva geracional que propicie uma mudança de direção nos questionamentos sobre a condição negra no Brasil.' O enfoque geracional pautado na análise das trajetórias educacionais possibilita avaliar comparativamente a situação de distintas gerações, ou seja, das diferenças e perspectivas de futuro dos mais jovens em relação aos seus pais. Outro aspecto abordado a partir desses novos enfoques trata da reconstituição em dados e idéias tanto do abandono ao qual os negros foram relegados ao longo de séculos pelas políiticas de Estado como das iniciativas tomadas em prol da própria educação desde o período colonial, após a abolição e durante a estruturação da nação independente. Tais pesquisas revelam uma atitude proativa mediante inúmeras tentativas de "a exemplo de outros grupos mais bem situados no jogo das relações políticas colocadas no cenário nacional nas primeiras décadas do século XX " empreender formas de superar as precárias condições de vida na sociedade industrial em crescente processo de urbanização e segregação socioespacial.

No entanto, apesar dos benefícios da expansão e da melhoria das redes de ensino, conforme indicadores produzidos desde o início dos anos 2000, crianças e jovens negros, bem como suas famílias, não são beneficiados por essas melhorias na mesma proporção que outros grupos raciais. Segundo Marcelo Paixão, ${ }^{2}$ vários aspectos resultantes de profundas desigualdades raciais que interferiam na apropriação de saberes e conhecimentos de cunho essencial foram significativamente alterados a partir da universalização da Educação Básica. Segundo o autor, outros indicadores educacionais correlatos e não menos importantes, como, por exemplo, os hiatos entre os grupos raciais, permaneceram inalterados ou evoluíram em ritmo extremamente lento.

Em relação à Educação Superior, o atual recurso às ações afirmativas como uma inovação instrumental do Estado na correção das desigualdades ${ }^{3}$ já emite avanços na superação de processos e práticas que excluíam estudantes oriundos dos estratos negros e indígenas dos espaços universitários públicos. Nestes primeiros 10 anos do milênio, consolida-se essa inquestionável conquista dos movimentos sociais, com expressivo vigor da pressão mobilizadora do Movimento Negro na obtenção dessas políticas, visando ao reconhecimento dos prejuízos do racismo e à reparação possível da dívida da sociedade brasileira com a cidadania dos homens e das mulheres que são portadores dos conteúdos histórico-culturais de uma das matrizes da sua nacionalidade. Nos últimos cinco anos, dentre vários desafios colocados no campo estratégico da educação, houve a aprovação de medidas de ação afirmativa em número crescente de universidades, como a Universidade de Brasília, que ocupa uma posição vanguardista como a primeira universidade federal a implementar o vestibular com cotas.

\footnotetext{
${ }^{1}$ Luiz Alberto Oliveira GONÇALVES e Petronilha B. G. SILVA, 2000, 2003.

2 Marcelo PAIXÃO, 2008.

${ }^{3}$ Ações políticas de caráter afirmativo e valorativo já constavam na pauta de entidades negras como a Frente Negra Brasileira na década de 1930 e do Teatro Experimental do Negro nas décadas de 1940-50, que traçaram uma veemente e incansável defesa da articulação dessas propostas com políticas universalistas de formação do cidadão (Sales A. SANTOS, 2007).
} 


\section{Ações afirmativas na Universidade de Brasília: implementação e repercussões}

A Universidade de Brasília conta atualmente com três processos de seleção: o sistema universal (vestibular), o Programa de Avaliação Seriada " PAS instituído em 1996 e o sistema de cotas, este último reserva $20 \%$ das vagas para estudantes que se autodeclaram negros e foi introduzido a partir do segundo vestibular de 2004. Além das vagas reservadas para estudantes negros, a UnB firmou um convênio de cooperação com a Fundação Nacional do Índio " Funai e vem realizando desde 2005 um vestibular diferenciado para estudantes indígenas. ${ }^{4}$

A implementação de cotas para estudantes negros na Universidade de Brasília surgiu no âmbito de discussões e acontecimentos sociais no final da década de 1990 , dentre eles a marcha em função do tricentenário da morte de Zumbi dos Palmares em 1995, a Conferência de Durban em 2001 e a crescente participação e atuação do Movimento Negro na universidade. Nesse sentido, as discussões sobre cotas para estudantes negros nas universidades brasileiras estão inseridas em um contexto maior de luta e combate ao racismo levado a cabo, sobretudo, pelos movimentos sociais. ${ }^{5}$ De acordo com os depoimentos dos conselheiros que atuavam no Cespe no ano de $2003,{ }^{6}$ a aprovação do projeto naquele momento foi motivada por um espírito "vanguardista", ou seja, de a UnB passar a ser a primeira universidade federal a introduzir um sistema de cotas para estudantes negros e, ao mesmo tempo, pelo contexto político, que criou uma "expectativa positiva" no que diz respeito às propostas e aos projetos do Governo Lula para a universidade pública. A implementação do sistema de cotas é vista como um "momento ímpar, histórico, transformador e necessário"7 no âmbito da universidade e da sociedade.

No segundo semestre de 2008, os cursos de graduação da Universidade de Brasília contavam com um total de 24.381 alunos distribuídos em 76 cursos nas modalidades presencial e a distância. O número de estudantes aprovados nos vestibulares pelo sistema de cotas desde o segundo vestibular de 2004 corresponde a 2.685 estudantes, sendo o número de estudantes do sexo masculino (1.493 estudantes) superior ao número de estudantes do sexo feminino ( 1.192 estudantes). ${ }^{8}$ Com relação à participação feminina em determinadas áreas do conhecimento, observa-se que as mulheres, independentemente da forma de ingresso, continuam sub-representadas na área de exatas, principalmente nos cursos de Engenharia, Física, Matemática, Estatística e Geologia. ${ }^{9}$

Após quatro anos de vestibulares consecutivos e duas turmas de formandos, ${ }^{10}$ as pesquisas sobre o desempenho e a evasão dos estudantes vêm contrariando as previsões negativas realizadas por aqueles que se posicionaram contrários à política de cotas; mostram um desempenho que pouco os tem diferenciado de outros estudantes. ${ }^{11}$ No que diz respeito à evasão (abandono do curso), Jacques Velloso e Claudete Cardoso afirmam que

\footnotetext{
${ }^{4}$ Segundo algumas estimativas, apenas $0,62 \%$ de 400 mil indígenas está matriculado no Ensino Superior. Com o convênio UnB/Funai, 200 estudantes índios entrarão na instituição até 2014 (UnB, 2008).

5 SANTOS, 2007.

${ }^{6}$ Os depoimentos foram coletados por Ernandes B. BELCHIOR, 2006.

7 BELCHIOR, 2006, p. 97.

${ }^{8}$ CESPE, UnB, 2008.

${ }^{9}$ Para mais detalhes, ver Wivian WELLER, 2008.

${ }_{10} \mathrm{Um}$ total de 44 estudantes que ingressaram pelas cotas em 19 cursos com quatro anos de duração concluíram seus estudos no primeiro semestre de 2008 (ADAC, 2008).

11 Jacques VELLOSO, 2007.
} 
os dados surpreenderam, pois alunos cotistas da instituição se evadem menos que nãocotistas, contrariando previsões dos críticos da reserva de vagas. Esses dados são auspiciosos e provavelmente refletem um maior empenho nos estudos por parte dos que ingressaram pela reserva de vagas. ${ }^{12}$

Os autores levantam a hipótese de que existe um maior apego e valorização do espaço conquistado por esses estudantes. As dificuldades enfrentadas para ingressar em uma universidade pública de prestígio como a UnB criam um elevado grau de determinação e de motivação para a continuidade dos estudos, mesmo entre aqueles que obtiveram menor desempenho nas disciplinas cursadas. Com base nesses dados, apresentaremos a seguir algumas experiências de estudantes que ingressaram pelo sistema de cotas.

\section{Trajetórias de jovens negras na Universidade de Brasília}

Embora já tenham sido realizadas algumas pesquisas sobre as trajetórias de escolarização das camadas médias e populares ${ }^{13}$ bem como sobre a escolarização das elites, ${ }^{14}$ ainda são poucos os estudos sobre os caminhos percorridos por jovens mulheres negras em direção ao tão sonhado e disputado ingresso em uma universidade pública. Nesse sentido, em nossa pesquisa sobre Trajetórias escolares e familiares de jovens mulheres que ingressaram pelo sistema de cotas na Universidade de Brasília, buscamos analisar como são constituídas as relações étnico-raciais e de gênero nos contextos sociais em que viveram e vivem, como reagem diante de práticas cotidianas de discriminação e como o ingresso na universidade por meio do sistema de cotas pode interferir no processo de (autoJrepresentação racial e de gênero. ${ }^{15} \mathrm{~A}$ coleta de dados está sendo realizada por grupos de discussão e entrevistas narrativas. ${ }^{16}$

No presente artigo optamos por apresentar um pouco da trajetória de três universitárias que passaram por processos de socialização escolar distintos, caracterizados pelos seguintes modelos: escola particular, escola pública e escola de caráter filantrópico mantida por uma instituição privada. Duas jovens freqüentam cursos predominantemente masculinos no campo das ciências exatas (Engenharia Mecânica e Engenharia de Redes); a outra estudante está cursando Ciências Sociais, curso misto no que diz respeito à proporção de homens e mulheres e de médio prestígio se comparado aos cursos de Engenharia. A seleção das entrevistas não constitui uma amostra representativa, mas se orienta pela construção de um corpus com base no conhecimento e na experiência das entrevistadas, analisadas com base no método documentário de interpretação. ${ }^{17}$ No âmbito deste artigo não nos será possível apresentar um conjunto maior de entrevistas que pudesse contemplar outros cursos

\footnotetext{
12 Jacques VELLOSO e Claudete CARDOSO, 2008, p. 15.

${ }^{13}$ Maria Alice NOGUEIRA, Geraldo ROMANELLI e Nadir ZAGO, 2000.

${ }^{14}$ Maria Alice NOGUEIRA e Ana Maria ALMEIDA, 2002.

${ }^{15} \mathrm{~A}$ pesquisa vem sendo realizada desde o segundo semestre de 2006 e conta com o financiamento do CNPq e da UnB. Participam ou participaram da pesquisa: Wivian Weller (coordenadora), Erika do Carmo Lima Ferreira (Doutoranda FE/UnB), Maria Auxiliadora G. P. Holanda (Mestre FE/UnB), Danielle Oliveira Valverde (Mestre FE/UnB), Ana Paula Meira (Mestranda FE/UnB), Priscila C. S. Souza (bolsista PIC-UnB/CNPq), Raquel Maria V. do Rosário (bolsista PIC-UnB/CNPq), Aline Pereira da Costa (bolsista Programa AfroAtitude/CNPq) e Nora Hoffmann (estagiária).

16 Para mais detalhes sobre os procedimentos teórico-metodológicos, ver: Ralf BOHNSACK, 2004; Sandra JOVCHELOVITCH e Martin BAUER, 2002; e WELLER, 2006. Até o presente momento foram realizados 16 grupos de discussão e 28 entrevistas narrativas, perfazendo um total de 66 estudantes.

17 BOHNSACK e WELLER, 2006; e WELLER, 2005.
} 
universitários e modelos de socialização escolar além dos acima apresentados. ${ }^{18}$ No entanto, as entrevistas selecionadas possibilitam um olhar sobre diferentes contextos familiares e escolares que podem ter influenciado na escolha do curso universitário, nas estratégias de enfrentamento do preconceito e da discriminação ou ainda nas posições assumidas por elas em relação às ações afirmativas, sobretudo em relação às cotas para estudantes negros na Universidade de Brasília.

\section{Breve descrição das trajetórias familiares das entrevistadas ${ }^{19}$}

Marcela, ${ }^{20} 19$ anos, é a caçula de uma família de quatro filhos oriunda do Estado de Goiás e de religião espírita. Seu pai é engenheiro agrônomo, atua no serviço público e recebe R\$ 6.000,00; a mãe cursou Educação Física, é servidora pública e recebe R\$ $1.200,00$, além de pensão alimentícia. Os pais se separaram quando Marcela tinha oito anos. No entanto, a jovem destaca que o pai "sempre buscava" ${ }^{21}$ os filhos no colégio e também nos finais de semana, compensando, dessa forma, o fato de não viver na mesma casa: "Pus isso na minha cabeça e deu certo [...] nunca cheguei a sofrer tanto assim". ${ }^{22}$ Marcela e seus irmãos sempre estudaram em escolas particulares. $O$ irmão mais velho concluiu um curso técnico em Agrimensura, é casado e "mora no interior"; a irmã mais velha concluiu a graduação em Publicidade e Propaganda. Marcela e seu outro irmão estão cursando Engenharia Mecânica na UnB. Antes de ingressar na UnB, Marcela cursou um semestre de Engenharia Mecânica em outro Estado. Resolveu prestar novo vestibular na UnB para estar mais próxima da cidade de origem e atualmente vive com mais duas estudantes em uma república nas proximidades da UnB. Destaca que, enquanto o seu irmão fez três semestres de cursinho para passar no vestibular, ela conseguiu ingressar no curso desejado após um único semestre de cursinho e um total de quatro vestibulares. Marcela sempre gostou de exatas, tendo participado de olimpíadas de Física e de Matemática. Escolheu o curso de Engenharia Mecânica por considerá-lo mais amplo do que outros cursos de engenharia e por ser um curso de graduação que facilita "montar, ter o próprio negócio, e você administrar isso". Com relação à escolha do curso, a jovem ainda relata: "Minha irmã sempre falou que eu ia fazer engenharia né, porque lá em casa quando o chuveiro queimava eu consertava assim, então sempre teve essa questão, o homem da casa tem hora que a gente ficava brincando assim né que o homem da casa que faz essas coisas era eu que ia trocava resistência de chuveiro e essas coisas [...]". ${ }^{23}$ Marcela recebe uma ajuda mensal dos pais equivalente a $\mathrm{R} \$ \mathbf{6 0 0 , 0 0}$ e utiliza-a para cobrir os gastos de aluguel, alimentação e outros.

Amanda, ${ }^{24} 21$ anos, é a mais velha de uma família de quatro filhos, cujos pais vieram de Estados do Nordeste para Brasília e residem em uma cidade no entorno da Capital Federal. Seu pai possui o ensino fundamental incompleto, trabalha como cozinheiro

\footnotetext{
${ }^{18}$ Sobre a experiência de estudantes de outros cursos e áreas do conhecimento, ver: Erika do Carmo Lima FERREIRA e Ana Paula MEIRA, 2009; Maria Auxiliadora G. P. HOLANDA, 2007; WELLER, 2007; WELLER e FERREIRA; 2009.

${ }^{19}$ Todos os nomes são fictícios. Também omitimos o semestre de ingresso das jovens para evitar a quebra de anonimato.

${ }^{20}$ Marcela em entrevista realizada por Wivian Weller e Aline Pereira em 28 de maio de 2007. As citações tomadas diretamente das entrevistas foram sinalizadas com aspas ou inseridas em parágrafo à parte.

${ }^{21}$ Marcela em entrevista realizada por Wivian Weller e Aline Pereira em 28 de maio de 2007.

22 Marcela em entrevista realizada por Wivian Weller e Aline Pereira em 28 de maio de 2007.

${ }^{23}$ Marcela em entrevista realizada por Wivian Weller e Aline Pereira em 28 de maio de 2007.

${ }^{24}$ Amanda em entrevista realizada por Wivian Weller e Raquel Vieira do Rosário em 14 de setembro de 2007.
} 
em um restaurante localizado no Plano Piloto e recebe $R \$ 700,00$ mensais. A mãe possui o ensino fundamental completo, já trabalhou como empregada doméstica e atualmente exerce a profissão "do lar" e de comerciante de um negócio montado na própria casa, sem renda declarada. Os pais de Amanda estão separados há 10 anos. Três filhos (inclusive Amanda) permaneceram com o pai e foram criados pela tia (irmã do pai de Amanda), que vive com a família desde os primeiros anos de vida de Amanda. A tia foi abandonada pelo marido por não ter voltado a engravidar após a perda de um feto no oitavo mês de gestação, e Amanda foi praticamente adotada pela tia como se fosse sua filha: "amo ela mais até que minha mãe, amo assim de paixão [...] não sinto a falta de minha mãe". ${ }^{25} \mathrm{~A}$ trajetória familiar de Amanda é marcada por dificuldades financeiras, por problemas na infância com o alcoolismo do pai - que fez com que a esposa o abandonasse com os filhos - e por problemas atuais com um dos irmãos, também alcoólatra. Amanda sempre estudou em escolas públicas localizadas no Gama (DF) e, ao concluir o Ensino Médio, foi auxiliada pela mãe que "não queria que [a filha] parasse de estudar", assim como pela antiga "patroa da mãe", que se dispôs a pagar o cursinho pré-vestibular, descontando os custos do salário da empregada. Contudo, o esforço de Amanda fez com que ela obtivesse um desconto de $80 \%$ do valor da mensalidade a partir do segundo semestre. Após cinco semestres de cursinho e cinco vestibulares, Amanda ingressou no curso de Engenharia de Redes na UnB. A opção pelo curso se deu em função do contato com os colegas do cursinho:

Aí eu queria muito entrar na engenharia né, porque eu já tinha entrado em contato com o pessoal da informática e eu já conhecia umas pessoas também lá. E conversava com um cara que fazia ciência da computação e eu queria porque queria fazer engenharia. Aí toda vez que eu ia fazer inscrição pro vestibular eu falava: Eu vou mudar porque tenho que entrar, não posso ficar a vida inteira no cursinho. Aí eu nunca mudava, assim né. Aí foi que eu passei, até que enfim né $[\ldots]^{26}$

Amanda recebe uma bolsa equivalente a $\mathrm{R} \$ 300,00$ e reside na Casa do Estudante Universitário da UnB. Está estudando para passar em algum concurso público para poder manter-se na universidade e também ajudar os seus irmãos mais novos a "entrar na UnB".

Ana, ${ }^{27} 20$ anos, de religião espírita, tem uma irmã de 14 anos e reside com os pais em Ceilândia (DF). Os pais são oriundos das regiões Centro-Oeste e Sudeste. Seu pai possui o ensino médio completo, trabalha como técnico em telecomunicação e tem uma renda equivalente a $\mathrm{R} \$ 600,00$. Sua mãe possui o ensino médio incompleto, trabalha como diarista e recebe $\mathrm{R} \$ \mathbf{8 0 0 , 0 0}$ mensais. Ana cursou o ensino fundamental em uma escola particular e o ensino médio em uma escola de caráter filantrópico mantida por uma instituição privada, ambas localizadas em Ceilândia (DF). Ana sempre quis estudar na UnB e nunca pensou em estudar em outra instituição. Tentou ingressar na universidade pelo PAS, freqüentou cursinhos pré-vestibulares com o apoio dos pais, prestou os dois primeiros vestibulares para o curso de Medicina e os três últimos para o curso de Ciências Sociais, sendo aprovada no quinto vestibular realizado na UnB. Ana recebe uma ajuda dos pais equivalente a $\mathrm{R} \$$ 250,00 para os gastos com "material para a faculdade" e atualmente não desenvolve nenhuma atividade remunerada. Declara estar gostando "cada dia mais" do curso e considera o campo da Sociologia "mais aberto" e "mais abrangente" que outras áreas.

\footnotetext{
${ }^{25}$ Amanda em entrevista realizada por Wivian Weller e Raquel Vieira do Rosário em 14 de setembro de 2007.

${ }^{26}$ Amanda em entrevista realizada por Wivian Weller e Raquel Vieira do Rosário em 14 de setembro de 2007.

${ }^{27}$ Ana em entrevista realizada por Ana Paula Barbosa Meira e Priscila Santos em 28 de maio de 2006.
} 


\section{Preconceitos velados na escola e na universidade}

Ao ser perguntada sobre sua infância, Marcela traz um pequeno relato que parece haver marcado sua forma de se posicionar diante do universo escolar e em relação aos colegas e professores:

Mf: Quando eu era mais nova meio que sofri tipo um preconceito, negra assim, eu não sou tão, mais de qualquer jeito acabou tendo. É: eu tenho muito cabelo e tive que cortá o cabelo por conta de piolho assim, então cortei fiquei com o cabelo bem curto como se fosse de homem muita gente já me rejeitava assim, e tal, as crianças né as meninas me chamando de homem, essas coisas $[\ldots] .{ }^{28}$

Sua primeira experiência de rejeição se dá a partir do corte de cabelo, que, nesse caso, também representou um corte de sua feminilidade na perspectiva das "menininhas do pré", visto que passou a ser tratada como homem, como diferente. A rejeição como menina em função do cabelo cortado faz com se distancie do universo feminino em uma fase da infância em que meninas costumam excluir o sexo oposto de seus jogos e brincadeiras. Uma vez excluída, Marcela passa a estabelecer amizades com outros grupos nos quais é aceita e respeitada: "Eu sempre andei muito com menino, a maioria dos meus amigos eram homens". ${ }^{29}$ A partir de um maior entrosamento com os meninos, ela também passa a se interessar por outras atividades consideradas tipicamente masculinas. Por possuir muitos amigos do sexo masculino e gostar das atividades realizadas por eles, sua atitude será questionada, para não dizer ridicularizada, por um professor que questiona sua ousadia e duvida de seus conhecimentos sobre futebol:

Mf: Teve um colégio que eu fiquei só seis meses e acho que por isso que não teve muita alteração no meu jeito de ser também já tava fazendo a $6^{a}$ série que tinha mais ou menos isso né. Igual o professor veio brincar comigo porque pedi pra ele deixar eu apitar o jogo ser juiz do jogo dos meninos de futebol e ele virou pra mim e falou: Óh se um goleiro de um lado ficar triste e o outro goleiro do outro lado ficar feliz é porque um time fez o gol e foi o gol do goleiro feliz.

Y1: Nossa!

Mf: Ai eu olhei assim né fiquei, achei, não fiz nada rir somente. Porque minha mãe é professora de educacao fisica então não seria tão besta de achar que um gol seria assim né $[\ldots]$. ${ }^{30}$

Além da situação acima narrada, é provável que outros problemas tenham ocorrido e culminado na saída desse colégio depois de seis meses. Embora a família nunca tenha mudado de cidade, Marcela relata haver estudado em seis colégios distintos ao longo de sua trajetória escolar. Os motivos para as mudanças não são detalhados, somente as dificuldades iniciais enfrentadas como, por exemplo, "entrar num ambiente onde todo mundo acaba se conhecendo e você lá é tipo um patinho feio". ${ }^{31}$ No entanto, essas experiências de mudança de colégio são relatadas como situações nas quais sempre foi capaz de superar as dificuldades iniciais e como oportunidades nas quais novas amizades, que perduram "até hoje", puderam ser constituídas. Marcela não explicita o que significa ser o "patinho feio" da sala de aula e, com exceção da primeira experiência de rejeição de seu cabelo curto, considera os demais comentários em relação ao seu cabelo como "mais normal":

Y1: E alguma experiência assim de, de racismo? Você lembra se aconteceu alguma coisa assim na escola no tempo em que você estudou? 
Mf: Sempre que alguma coisa que tinha seria só por conta do cabelo mesmo, meu cabelo era mais crespo [...] porque eu não sou tão escura assim morena-mulata como dizem [...] Mas aí só. Nunca tive preconceito de cor assim não [...] nunca vivenciei um diretamente, talvez indiretamente alguém chamou: Ah aquela neguinha alguma coisa assim alguma coisa assim, mas nunca pessoalmente, não.

Y1: Hm.

Mf: tranquilo assim, nessa questão, acho que é, porque eu sempre depois dessa coisa de ser tímida, mais sempre depois que eu conhecia as pessoas eu tentava fazer amizade assim, ser o mais coerente possível certo não fazer nada de errado assim que prejudique o colega, então eu acho que as pessoas sempre me respeitavam assim, até hoje assim, tem umas pessoas que me chamam de mãe, falam que eu tenho esse instinto de mãe de sempre acolher as pessoas e tal. Então eu nunca tive problema com racismo não, a questão a única coisa que lembro é cabelo, cabelo todo mundo fica falando né é uma coisa acho mais normal de falar de cabelo, só.

Y2: Mas a questão do cabelo foi só na época que você cortou ou não?

Mf: Não, depois também mais na frente eh agora que mais velha que o cabelo cresce pesa e já não faz tanta não faz tanta diferença, mas eu sempre tive de alguma pessoa comentar alguma coisa do cabelo não só quando eu cortei.

O fato de não ser "tão escura", de ter sido uma aluna que procurava ser "o mais coerente possível" e de "não fazer nada de errado" foi um aspecto que garantiu respeito entre colegas na escola. Ao mesmo tempo "seu instinto de mãe" e de alguém que "acolhe as pessoas" também contribuiu para um tipo de convivência que leva Marcela a ponderar algumas brincadeiras ou comentários como "normais". Considerar comentários freqüentes em relação ao seu cabelo ${ }^{33}$ como "normais" constitui uma estratégia de convivência com o outro com base no não enfrentamento direto, evitando o confronto e a denúncia de determinadas posições e atitudes. Não se trata de uma postura de resignação ou de passividade diante do racismo e do preconceito, mas, sobretudo, de uma tentativa de minimização de conflitos adotada no âmbito das relações sociais com grupos que fazem parte do convívio diário. ${ }^{34}$

Amanda e Ana não relataram situações de preconceito nas escolas em que estudaram. No caso de Amanda, a ênfase ao longo de toda a sua narrativa recaiu sobre os problemas e as dificuldades enfrentadas pela família. Ana realiza uma avaliação bastante positiva, destacando o "trabalho totalmente voltado para a comunidade" desenvolvido pela escola, assim como a equipe de professores formada por pessoas "altamente sensíveis" e "muito bacanas":

Y1: Como que era a relação éh dos professores da Escola FN com os alunos?

\footnotetext{
${ }^{28}$ Marcela em entrevista realizada por Wivian Weller e Aline Pereira em 28 de maio de 2007. Leia-se: M (Marcela), f (feminino), Y1 (entrevistadora principal) e Y2 (segunda entrevistadora). Sobre os códigos de transcrição adotados, ver WELLER, 2006.

${ }^{29}$ Marcela em entrevista realizada por Wivian Weller e Aline Pereira em 28 de maio de 2007.

${ }^{30}$ Marcela em entrevista realizada por Wivian Weller e Aline Pereira em 28 de maio de 2007.

${ }^{31}$ Marcela em entrevista realizada por Wivian Weller e Aline Pereira em 28 de maio de 2007.

${ }^{32}$ Marcela em entrevista realizada por Wivian Weller e Aline Pereira em 28 de maio de 2007.

${ }^{33}$ Sobre a reprodução de estereótipos em relação ao corpo negro e cabelo crespo, ver estudos realizados por Nilma Lino GOMES, 2002, 2006.

${ }^{34}$ Estratégias semelhantes também foram observadas entre alguns grupos paulistanos pertencentes ao Movimento Hip-hop (WELLER, 2007a, 2009).
} 
Af: Ah era boa a relação assim. Eu particularmente nunca tive assim problemas com professor assim e com problemas que às vezes que assim que a gente enxerga né porque as pessoas têm tiveram professores assim [...] sabe excesso de conversa com os alunos ou outro desrespeito com professor na sala de aula e tal. Mas assim eu nas minhas turmas eu por exemplo nunca tive problemas assim que chamasse muita atenção com professor né sempre respeitava e tal $[\ldots]^{35}$

A jovem cursou o ensino médio em uma escola cuja equipe estava envolvida com a comunidade, com o "convívio social na escola" e com a construção da personalidade dos alunos ("na construção do que a gente se forma do que a gente é"). Ainda que, em relação aos "conteúdos formais", a qualidade da escola estivesse aquém do necessário para ingressar no curso inicialmente pretendido (Medicina), Ana valoriza a formação para a cidadania e a educação para o respeito às diferenças recebidas na escola. Ao ingressar na universidade, surpreende-se com situações até então desconhecidas, entre outras, a posição assumida por alguns professores. No segmento a seguir, Ana apresenta um longo relato sobre conflitos surgidos em uma disciplina:

Af: [...] eu tenho uma aula assim meu professor [...] tem dias que ele resolve soltar umas pérolas assim durante a aula [...] Aí quando tava tendo sabe aquele seminário que teve "A Universidade contra o preconceito" [...] Aí foi colado pela universidade toda uns cartazes e tinha um cartaz que traz assim grandes pensadores e filósofos e tal e frases preconceituosas né e eles colocaram assim no slogan "Nem grandes nem pensadores" porque eles fazem parte daquela Coleção Grandes Pensadores né. Aí eles colocaram "Nem grandes nem pensadores" e colocaram a frase e colocaram o nome assim e tinha vários tinha Hegel tinha Nietzsche deu pra entender né esse cartaz e tal. Aí até que um dia ele chegou na sala muito indignado mesmo éh falando né que não sei o que que não concordava com isso que isso era uma onda que tava tomando a universidade que ele não enxergava aqui no Brasil preconceito [...] aí ele falando que no Brasil não existia preconceito que não sei o que se for comparar o Brasil com os Estados Unidos nãnãnã um monte de coisas que não tinha nem comparação e tal né [...] Aí eu lembro que deu muita polêmica [...] aí depois teve uma aula mais na frente e tal aí ele falou que tudo que escreviam sobre o Movimento Negro, sobre o Movimento das Mulheres, sobre o Movimento Gay fudo isso ele falou que era panfletagem chegou na sala falando que isso aí era panfletagem e tal ele falou uma série de outras coisas meio absurdas e tal. Aí teve um menino que ficou muito indignado nesse dia ele se retirou né [...] Aí inclusive o garoto falou: Não realmente é professor eu tô começando a achar que você acha que gays, mulheres e negros não tem direito não né [...] ele se exaltou e o professor ficava sem jeito de falar sabe o professor não conseguia fazer ele parar de falar sabe [...] Aí depois que o rapaz falou tudo que ele queria dizer e tal, aí ele respondeu a chamada e foi embora né. Aí o professor ficou se justificando dizendo que tinha muita dó desse aluno que não sei o quê, que tinha muita dó porque ele achava que podia rodar 0 mundo com esse discursinho dele que o mal era esse discursinho [...] e foi um dia assim um grande rebuliço assim $[\ldots]{ }^{36}$

Três componentes se destacam na narrativa do episódio que causou espanto e perplexidade entre Ana e os demais estudantes: em primeiro lugar, os jovens não esperavam encontrar um professor com formação em Ciências Humanas assumindo um discurso de negação da existência do racismo na sociedade brasileira e de subestimação dos movimentos sociais - que ao longo das últimas décadas vêm denunciando a discriminação

\footnotetext{
${ }^{35}$ Ana em entrevista realizada por Ana Paula Barbosa Meira e Priscila Santos em 28 de maio de 2006.

${ }^{36}$ Ana em entrevista realizada por Ana Paula Barbosa Meira e Priscila Santos em 28 de maio de 2006.
} 
de mulheres, negros e homossexuais em distintos contextos, sobretudo nas instituições de ensino e no mercado de trabalho - e afirmando tratar-se apenas de "panfletagem"; 0 segundo aspecto está relacionado à postura do professor diante do estudante que arrisca questionar sua posição como docente dando a seguinte sugestão: "Você podia se limitar, dar o seu conteúdo e não emitir a sua opinião". Não havendo qualquer possibilidade de comunicação diante da hierarquia estabelecida pelo professor em sala de aula, o jovem se retira e, em seguida, passa a ser alvo de comentários com proporções de um cerimonial de degradação, como descrito por Harold Garfinkel. ${ }^{37}$ Diante do 'atrevimento' do estudante, que rompe com a hierarquia professor/aluno, e vendo-se na função de restabelecer a ordem após o caos instaurado em sala de aula, o professor se utiliza de instrumentos mais uma vez não esperados em um curso no campo das Ciências Humanas, ${ }^{38}$ tais como a ironia ("dó desse aluno") e a depreciação ("discursozinho") dos argumentos daqueles que, do ponto de vista geracional (jovens) e da posição social ocupada (alunos), são vistos como hierarquicamente inferiores; o terceiro aspecto está relacionado à insensibilidade ou incapacidade de perceber a universidade como um espaço plural no qual existe a "liberdade [...] de falar", mas também deve existir "o limite e o respeito" com idéias contrárias.

O relato detalhado dessa experiência ${ }^{39}$ pode ser visto ainda em oposição à postura que Ana conhecia de seus professores do Ensino Médio. Segundo a entrevistada, existia uma reciprocidade de perspectivas entre professores e alunos, uma disposição para ouvir e para falar assim como uma relação de respeito às diferenças, como narrado a seguir:

Af: [...] nunca percebi assim que tivesse uma diferenciação assim de gênero de chamar mais meninos ou meninas pra determinada atividade porque assim os grupos eram bem heterogêneos [...] a relação lá na Escola $F N$ assim tipo todo mundo conhece todo mundo [...] tirando raras exceções que entram no $2^{\circ}$ grau mas a grande maioria das pessoas estão lá desde pequena assim sabe desde o pré o pessoal faz desde o pré junto assim e então assim todo mundo conhece todo mundo. Então sabe eu não percebo uma relação assim sabe só umas piadinhas assim [...] mas não era o professor era os próprios alunos sabe, professores eu eu não lembro nenhum professor que tenha soltado qualquer piadinha em relação à gênero.

Y1: Nem à raça?

Af: Nem à raça.

Y1: E aluno?

Af: Aluno já. Assim, mas eram éh são situações bem esporádicas, muito esporádicas mesmo não são constantes não [...] Eu já tive debates assim muito em salas de aula e tal falando sobre essas coisas então os professores eles tinham uma maneira bem tranqüila de lidar com esses assuntos sabe conversava e tal. Não tinha aquela é maneira ah, eu vejo o meu mundo aqui então sabe eles eram muito abertos assim pra escutá e tal e pra falá. Assim nunca foi uma fala assim de certa forma que desrespeitasse assim ou pelo fato de você ser branco ou pelo fato de você ser negro [...].

\footnotetext{
${ }^{37}$ Harold GARFINKEL, 1956.

${ }^{38}$ Ana em entrevista realizada por Ana Paula Barbosa Meira e Priscila Santos em 28 de maio de 2006. "Justamente [no] curso de História no curso de Sociologia né".

${ }^{39} \mathrm{O}$ tempo de narração equivale a cerca de 10 minutos de gravação.

${ }^{40}$ Ana em entrevista realizada por Ana Paula Barbosa Meira e Priscila Santos em 28 de maio de 2006, grifos nossos. O docente envolvido no episódio narrado atuava como professor substituto e não mais se encontra na UnB.
} 


\section{Percepções sobre o sistema de cotas da Universidade de Brasília}

A opção pelo vestibular com cotas não é uma decisão tomada com facilidade pelos estudantes em função da polarização de opiniões sobre essa política tanto entre intelectuais brasileiros quanto nas notícias vinculadas nos principais meios de comunicação. ${ }^{41}$ Nas entrevistas realizadas com estudantes oriundas de escolas particulares que prestaram os primeiros vestibulares pelo sistema de cotas, existia o receio de uma possível estigmatização como cotistas e associação de estudantes que "pegaram a vaga de alguém", ou seja, de um estudante que não pode entrar pelo sistema universal em função da diminuição de vagas nessa modalidade. ${ }^{42}$ Passados alguns vestibulares, 0 receio de um possível questionamento em relação ao "nível" daqueles que ingressam pelas cotas, sobretudo nos cursos de alto prestígio (Medicina, Direito e Engenharias), deixou de ser um motivo de preocupação, uma vez que as notas alcançadas por esses estudantes em pouco se diferenciam daqueles que disputam uma vaga pelo sistema universal. ${ }^{43}$ Percebe-se, no entanto, uma espécie de culpa ou peso de consciência por estarem usufruindo de uma "brecha" criada pelo sistema de cotas e ocupando uma vaga que poderia ser preenchida por um estudante oriundo da escola pública, como narrado por Marcela, do curso de Engenharia Mecânica:

Y1: E os dois vestibulares que você fez aqui foi o vestibular pra cotas ou como é que foi? Mf: Um foi, acho que eu fiz quatro [...] os dois primeiros não foi por cota e os dois segundos já foi por cotas. Porque assim eu pensava não fazer por cotas porque como o meu nível escolar era, como eu estudei nos melhores colegios da cidade $L X$ então não tinha essa necessidade porque a gente pensa na cota mais prá quem tem a necessidade mesmo de passar " precisa da cota por causa do ensino público não é bom [...] e fiz esses dois vestibulares só sem cotas só que aí depois nos dois últimos eu já tava meio quando você fica meio descrente assim e fica pensando que não vai passar em lugar nenhum [...] Mas igual oportunidade já que ofereceu e essa questão não tá não tá sendo eh bem usada, então se eu tenho a oportunidade se eu posso usar então usarei acabei pensando assim, ai eu fiz fui lá tirei a foto [...] aí acabei usando a cota com medo de não passar e ter que enfrentar de novo o ensino o cursinho que é muito cansativo ficar no cursinho, o meu cursinho a gente era praticamente de domingo a domingo então era muito cansativo, aí eu acabei aderindo a cota [...] a gente às vezes cansa de ficar prestando vestibular [...] acaba aproveitando uma brecha que o governo acabou deixando né, que não é só prá quem essa cota não é só prá negros que fizeram ou tiveram um ensino médio um ensino.

Y1: Escola pública.

Mf: É escolas públicas ensino no geral né [...] eu acabei aproveitando essa brecha deles [...] como tinha essa brecha eu acabei aproveitando né [...] Então ela é um sistema meio falho mais também ela dá oportunidade à muitos que não ia conseguir entrar se não fosse por ela né $[\ldots]$. ${ }^{44}$

Marcela compreende o sistema de cotas como uma política que "não está sendo bem usada" e como um "sistema meio falho" que concede direitos àqueles que - tal como ela-estudaram em boas escolas e não teriam "essa necessidade". A política de cotas na sua avaliação deveria se configurar como um mecanismo de distribuição de vagas àqueles

${ }^{41}$ Sobre esse assunto, ver Karine GOSS, 2008.

42 WELLER, 2007; e WELLER, FERREIRA e MEIRA, 2009.

${ }^{43}$ Para mais informações sobre desempenho e rendimento de estudantes que ingressaram pelo sistema de cotas e por outras modalidades, ver: VELLOSO e CARDOSO, 2008.

${ }_{44}$ Marcela em entrevista realizada por Wivian Weller e Aline Pereira em 28 de maio de 2007. 
que não tiveram acesso a uma educação escolar de qualidade. A dimensão das cotas como uma política de ação afirmativa e de reconhecimento das desigualdades que não se configuram apenas como desigualdades socioeconômicas e como uma política que insere no contexto universitório a discussão sobre as desigualdades entre brancos e negros na sociedade brasileira não é percebida pela jovem. Ao mesmo tempo Marcela reconhece que a escola particular por si só não garante o acesso aos cursos mais disputados nas universidades federais. Fundamentais para $\circ$ ingresso no curso pretendido são a persistência e a predisposição física e psicológica ("de domingo a domingo") para os semestres de cursinho pré-vestibular subseqüentes à conclusão do ensino médio. Em sua narrativa, duas realidades são caracterizadas como injustas: por um lado, a "brecha que - governo acabou deixando", permitindo aos jovens negros egressos de escolas particulares o acesso à universidade pelo sistema de cotas; e, por outro, a batalha física e psicológica enfrentada nos cursinhos pré-vestibulares. Nesse sentido, a política de cotas também se constitui como uma oportunidade para muitos que não entrariam "se não fosse por ela", ou seja, para aqueles que não estão em condições de freqüentar quatro ou cinco semestres de cursinho num regime de estudos e de pressão psicológica que tem como objetivo somente o domínio de conteúdos que serão cobrados nos vestibulares e que, em muitos casos, pouco contribuirão para a formação profissional pretendida.

Amanda, do curso de Engenharia de Redes, percebe que no momento atual o sistema de cotas "está sendo bom", uma vez que permitiu que estudantes negros e oriundos de escolas públicas pudessem ingressar na universidade, sobretudo nos cursos mais disputados:

\section{Y2: Como você enxerga hoje o sistema de cotas?}

Af: Como que eu enxergo o sistema de cotas? Deixa eu pensar uma forma @como dizê isso@ [pausa] Eu acho assim que que não é uma coisa que tem que ser feita pra vida inteira entendeu? Por que assim eu acho que não só você éh colocando o sistema de cotas na universidade por um tempo indeterminado que vai resolver o problema [...] Porque a gente sabe que o problema não tá só aqui na universidade, tá fora da universidade também que às vezes muitas pessoas negras não têm acesso ao mercado de trabalho pelo fato de ser negra então assim eu acho que o governo tem que investir não só no nível superior e começar do da primeira série em diante [...] Porque assim [...] na UnB hoje em dia tem mais pessoas ricas do que pessoas pobres porque as pessoas a maioria das pessoas que eu conheço acham que falam assim ah a UnB é coisa pra rico é público mas é de rico então assim tanto é que lá lá onde a minha mãe mora né quando a minha mãe falou prá todo mundo que eu tô na UnB aí nossa ah num sei quê e tal todo mundo acha que é coisa de outro mundo né entrá na UnB. Mas você sabe que entrá na UnB é fichinha né o duro @ é saí daqui@ [...] Eu acho que o sistema de cotas nesse momento tá sendo bom mas depois não vai resolver nada porque só vai colocar o povo no mercado de trabalho aí daqui uns dias vai ter que abrir cotas pro mercado de trabalho também porque da universidade vai tá saindo muitas pessoas negras e essas pessoas negras não vão ter onde trabalhar porque a a empresa as empresas privadas são racistas $[\ldots]$. ${ }^{45}$

Diante das dificuldades atuais de permanência no curso, Amanda considera 0 ingresso na UnB "fichinha" e a saída com o diploma, um "duro" caminho a ser percorrido. ${ }^{46}$

\footnotetext{
${ }^{45}$ Amanda em entrevista realizada por Wivian Weller e Raquel Vieira do Rosário em 14 de setembro de 2007.

${ }^{46}$ Amanda relata que em seu curso quase todos os livros a serem comprados são publicados nos Estados Unidos. Por não dispor de condições financeiras nem para realizar as fotocópias, a jovem conta com a ajuda do namorado, que leva os exemplares emprestados dos colegas para copiar em seu local de trabalho. Nesse sentido, a Caixa Econômica Federal - sem tomar conhecimento do fato - está contribuindo significativamente para a permanência da estudante na universidade.
} 
Ao término dessa etapa, a jovem prevê outras dificuldades que surgirão na disputa por um emprego formal. Se não houver uma política de abertura de vagas no mercado de trabalho, os problemas enfrentados atualmente não serão resolvidos. Quando sugere que o governo deveria investir "não só no nível superior", mas "começar da primeira série", Amanda parece acreditar que os problemas em relação ao acesso à educação e posteriormente ao mercado de trabalho estariam resolvidos. No entanto, avalia que as "empresas privadas são racistas" e, em outro momento da entrevista, traz a perspectiva do concurso público como uma das poucas saídas para o problema. Amanda não vislumbra a possibilidade de mudança da política de contratação das empresas por meio de uma mudança mais ampla dos discursos vigentes na sociedade brasileira que poderia ou deveria acontecer nos espaços em que esses futuros profissionais estão sendo formados. Quando destaca a necessidade de o governo investir na formação dos futuros profissionais desde a "primeira série", Amanda se refere ao papel do Estado no que diz respeito à qualidade da educação. A função do Estado, sobretudo da escola e da universidade na luta contra o racismo e a discriminação, não é tematizada.

A compreensão de que políticas distributivas não são suficientes para o enfrentamento do racismo e da discriminação, fazendo-se necessária uma transformação mais ampla por meio do "diálogo" e da discussão em torno dos "preconceitos" existentes, constitui o cerne da reflexão de Ana, do curso de Ciências Sociais:

Y1: Dessa tríade racismo, preconceito e ações afirmativas éh quê que você acha dessas questões?

Af: Én, bem, assim eu acho mais importante de tudo é você conversar sobre isso né discutir sobre as coisas conversar com as pessoas né [...] porque eu sou totalmente a favor das ações afirmativas dessas questões assim super a favor de conversar sobre os preconceitos assim sabe [...] eu acho interessante pra gente meio que despertar e tal sobre as ações afirmativas. Eu acredito assim que ela ela existe porque em algum momento tem alguém que tá sendo negado né [...] você meio que desaparece do contexto social em algum momento né. Então acho elas são super válidas [...] elas foram construídas assim porque por exemplo as pessoas éh por exemplo a questão das cotas né assim se existisse uma equiparação entre as pessoas se não existisse essa diferença entre as pessoas de tratamento com as pessoas, de oportunidades com as pessoas, você não insistiria numa necessidade de ter ações afirmativas né. Porque se existe ações afirmativas porque em algum momento alguém tá sendo negado né dentro do processo e alguém tá sendo deixado de lado né [...]. Então acho que conversar sobre isso eu acho que é uma coisa certa sim [...] pra você ter a noção do que tá acontecendo sabe, mais do que você transformar, eu acho que antes de você transformar você tem que falar sobre isso né, porque às vezes as pessoas querem transformar sem discutir [...]. ${ }^{47}$

Ana percebe a dimensão distributiva da política de cotas que concede o acesso à universidade a "alguém [que] tá sendo negado né dentro do processo" e que "desaparece do contexto social". No entanto, outras dimensões da política se fazem presentes na medida em que se autorizam o acesso e o direito à voz àqueles que até há pouco tempo não freqüentavam uma universidade pública. Também surgem os conflitos e a necessidade de se "conversar sobre os preconceitos". Nesse sentido, o ingresso de estudantes negros de distintos contextos sociais provoca uma mudança no interior da universidade, levando professores e alunos a discutirem e a se posicionarem sobre questões até há pouco tempo

\footnotetext{
${ }^{47}$ Ana em entrevista realizada por Ana Paula Barbosa Meira e Priscila Santos em 28 de maio de 2006.
} 
silenciadas ou negligenciadas nesse espaço. Segundo a entrevistada, existe uma tendência apontando para uma transformação do contexto universitário como pouco aberto ao diálogo: "As pessoas querem transformar sem discutir". Em outras palavras: os estudantes que ingressaram pelo sistema de cotas se sentem contemplados no que diz respeito à vaga que lhes foi concedida, mas criticam a falta de diálogo e o fato de não estarem sendo ouvidos por aqueles que estão empenhados em "transformar" a universidade.

\section{Algumas considerações}

Atualmente, alguns setores institucionais públicos e parte considerável da sociedade civil se mostram sensíveis a políticas de Estado para promover a igualdade e combater 0 racismo, a xenofobia e as múltiplas formas de discriminação e intolerância. No cenário internacional, as nações se preparam para retomar e avaliar os ganhos sociais com a implementação das propostas traçadas em Durban, no ano de 2001. O final desta década apresenta-se propício à mobilização social para retomar na agenda política e de desenvolvimento nacional metas concernentes ao projeto de sociedade democrática multicultural e igualitária, as quais deverão entrar na revisão do Plano Nacional de Educação - PNE. Apontamentos de análise das medidas em curso disponíveis, embora parcialmente desenvolvidos, permitem identificar virtudes e falhas, e avaliar e redirecionar o que está sendo feito. Os dados relativos às experiências escolares e vivências universitárias, tais como os dados apresentados neste artigo, confirmam nosso entendimento de que a resolução de problemas "crônicos" de desenvolvimento coletivo, produzidos por imbricados e sistemáticos processos de alijamento, seja de amplos setores socioculturais, grupos ou categorias de pessoas, ainda constitui um grande desafio. A esperança de resultados palpáveis, depositada nas ações afirmativas, exige a tomada de outras medidas nacionais, regionais e locais. ${ }^{48}$ Depende ainda que o crescimento econômico visado pelas políticas específicas esteja associado ao combate às desigualdades e com o aperfeiçoamento institucional democrático.

Concordamos que não adianta a medida ser justa e estar de acordo com os imperativos da justiça social se ela não produz resultados. Nesse sentido, a ampliação do debate sobre multiculturalismo, políticas da diferença e políticas de reconhecimento ${ }^{49}$ é fundamental se quisermos promover uma ruptura dos essencialismos e binarismos muitas vezes presentes nos debates educacionais, se quisermos promover a análise crítica e criativa das relações entre sujeitos diferentes, se quisermos criar condições para que as especificidades e as conflitualidades dessas relações sejam compreendidas, se quisermos promover - tanto no âmbito da escola como em outros espaços educativos - formas emancipatórias de relação social que favoreçam a superação dos processos de sujeição e exploração que têm marcado nossa história. A universidade deve incorporar a discussão sobre o hibridismo - no sentido elaborado por Bhabha -, ou seja, como principal componente de nossas identidades e das construções culturais, sem privilegiar nem a unidade fundamental da cultura e nem a diversidade irredutível das culturas. Para vivermos juntos, deve ser possível aprendermos a ver que o outro é uma figura possível de mim como eu dele, experimentar esse descentramento mútuo observador/observado. Assim, as nossas identidades passam a ser apreendidas do interior das nossas diferenças, a partir das relações e, por que não, de nossas discussões.

${ }^{48}$ João FÉREZ JÚNIOR e Jonas ZONINSEIN, 2006.

${ }^{49}$ Sobre esse tema, ver: Nancy FRASER, 2001, 2002; Joan W. SCOTT, 2005; Maris YOUNG, 2006. 


\section{Referências bibliográficas}

ADAC. Assessoria de Diversidade e Apoio aos Cotistas. 2008.

BELCHIOR, Ernandes B. Não deixando a cor passar em branco: o processo de implementação de cotas para estudantes negros na Universidade de Brasília. 2006. Dissertação (Mestrado em Sociologia) " Universidade de Brasília, Brasília, 2006.

BOHNSACK, Ralf. "Group Discussions and Focus Groups". In: FLICK, Uwe; KARDOFF, Ernst von; STEINKE, Ines (Orgs.). A Companion to Qualitative Research. London: SAGE, 2004. p. 214221.

BOHNSACK, Ralf; WELLER, Wivian. "O método documentário e sua utilização em grupos de discussão". Educação em Foco, Juiz de Fora, v. 11, n. 2, p. 19-38, 2006.

CARDOSO, Claudete B. Efeitos da política de cotas na Universidade de Brasília: uma análise do rendimento e da evasão. 2008. Dissertação (Mestrado em Educação) - Faculdade de Educação, Universidade de Brasília, Brasília, 2008.

CESPE. Centro de Seleção e de Promoção de Eventos. Universidade de Brasília - UnB. 2008. Disponível em: http://www.cespe.unb.br/. Acesso em: set. 2008.

FERREIRA, Erika do Carmo Lima. A construção da identidade e da diferença: sobre políticas de cotas e poder de representação. 2009. Tese (Doutorado em Educação) "Universidade de Brasília, Brasília, 2009.

FRASER, Nancy. "Da redistribuição ao reconhecimento? Dilemas da justiça na era póssocialista". In: SOUZA, Jessé (Org.). Democracia hoje: novos desafios para a teoria democrática contemporânea. Brasília: UnB, 2001. p. 245-282.

"Políticas feministas na era do reconhecimento: uma abordagem bidimencional da justiça de gênero". In: BRUSCHINI, Cristina; UNBEHAUM, Sandra (Orgs.). Gênero, democracia e sociedade brasileira. São Paulo: Ed. 34, 2002. p. 61-78.

GARFINKEL, Harold. "Conditions of Successful Degradation Ceremonies". American Journal of Sociology, Chicago, v. 61, p. 420-424, 1956.

GOMES, Nilma Lino. "Trajetórias escolares, corpo negro e cabelo crespo: reprodução de estereótipos ou ressignificação cultural?". Revista Brasileira de Educação, Rio de Janeiro, n. 21 , p.40-51, dez. 2002.

. Sem perder a raiz. Corpo e cabelo como símbolos da identidade negra. Belo Horizonte: Autêntica, 2006.

GONÇALVES, Luiz Alberto Oliveira; SILVA, Petronilha B. G. "Movimento Negro e educação". Revista Brasileira de Educação, São Paulo, v. 15, n. 15, p. 134-158, 2000.

. "Multiculturalismo e educação: do protesto de rua a propostas políticas". Educação e Pesquisa, São Paulo, v. 29, n. 1, p. 109-125, 2003.

GOSS, Karine Pereira. Retóricas em disputa: o debate entre intelectuais em relação às políticas de ação afirmativa para estudantes negros no Brasil. 2008. Tese (Doutorado em Sociologia Política) “ Universidade Federal de Santa Catarina, Florianópolis, 2008.

FÉREZ JÚNIOR, João; ZONINSEIN, Jonas (Orgs.). Ação afirmativa e universidade: experiências nacionais comparadas. Brasília: Editora da UnB, 2006.

HOLANDA, Maria Auxiliadora G. P. Trajetórias de vida de jovens negras da Universidade de Brasília no contexto das ações afirmativas. 2007. Dissertação (Mestrado em Educação)

"Universidade de Brasília, Brasília, 2007.

JOVCHELOVITCH, Sandra; BAUER, Martin W. "Entrevista narrativa". In: BAUER, Martin W.; GASKELL, George (Orgs.). Pesquisa qualitativa com texto, imagem e som. Um manual prático. Petrópolis: Vozes, 2002. p. 90-113.

NOGUEIRA, Maria A.; ALMEIDA, Ana Maria F. A escolarização das elites - um panorama internacional da pesquisa. Petrópolis: Vozes, 2002. 
NOGUEIRA, Maria A.; ROMANELLI, Geraldo; ZAGO, Nadir. Família e escola. Trajetórias de escolarização em camadas médias e populares. Petrópolis: Vozes, 2000.

PAIXÃO, Marcelo. A dialética do bom aluno: relações raciais e sistema educacional brasileiro. Rio de Janeiro: FGV, 2008.

SANTOS, Sales A. Movimentos negros, educação e ações afirmativas. 2007. Tese (Doutorado em Sociologia) “ Universidade de Brasília, Brasília, 2007.

SCOIT, Joan W. "O enigma da igualdade". Revista Estudos Feministas, Florianópolis, v. 13, n. 1, p. $11-330,2005$.

SILVEIRA, Marly. Educação, diferenças e desigualdade: a contribuição da escola neste enfrentamento. 2002. Tese (Doutorado em Psicologia) “ Universidade de São Paulo, São Paulo, 2002.

. "Estratégias pedagógicas e abordagem racial". In: BERNARDINO, Joaze; GALDINO, Daniela (Orgs.). Levando a raça a sério: ação afirmativa e universidade. Rio de Janeiro: DP\&A, 2004. p. 241-251.

UnB. Universidade de Brasília. Secretaria de Comunicação. 2008. Disponível em: www.unb.br/ acs/unbagencia/ag0606-17.htm. Acesso em: 13 out. 2008.

VELLOSO, Jacques R. Cotistas e não-cotistas: rendimento de três turmas de alunos da UnB. Brasília: NESUB e Faculdade de Educação da UnB, 2007. 21 p. Mimeografado.

VELLOSO, Jacques R.; CARDOSO, Claudete B. Evasão na Educação Superior: cotistas e nãocotistas na Universidade de Brasília. In: $31^{a}$ REUNIÃO ANUAL DA ANPED, 2008, Caxambu/ MG. Anais... Caxambu/MG, 2008.

WELLER, Wivian. "A contribuição de Karl Mannheim para a pesquisa qualitativa: aspectos teóricos e metodológicos". Sociologias, v. 7, n. 13, p. 260-300, jan./abr. 2005. Disponível em: www.scielo.br/pdf/soc/n13/23564.pdf. Acesso em: set. 2008.

"Grupos de discussão na pesquisa com adolescentes e jovens: aportes teóricometodológicos e análise de uma experiência com o método". Educação e Pesquisa, São Paulo, v. 32, p. 241-260, maio/ago. 2006. Disponível em: www.scielo.br/pdf/ep/ v32n2/a03v32n2.pdf. Acesso em: set. 2008.

. "Estratégias de enfrentamento das discriminações geracionais através do hip hop". In: WOLFF, Cristina Scheibe; FÁVERI, Marlene de; RAMOS, Tânia Regina O. (Orgs.). Leituras em rede: gênero e preconceito. Florianópolis: Editora Mulheres, 2007a. p. 159-175.

"Diferenças e desigualdades na Universidade de Brasília: experiências de jovens negras e suas visões sobre o sistema de cotas". Politica \& Sociedade, Florianópolis, UFSC, v. 6, p. 133-158, 2007b.

. "Redução das desigualdades de gênero e raça na Universidade de Brasília". In: GÊNNERO E INDICADORES DA EDUCAÇÃO SUPERIOR BRASILEIRA, 2008, Brasília: Inep. p. 153176.

. Minha voz é tudo o que eu tenho. Práxis estética e experiências discriminatórias de jovens negros em São Paulo e jovens turcos em Berlim. Belo Horizonte: UFMG, 2009. No prelo.

WELLER, Wivian; FERREIRA, Erika do Carmo Lima; MEIRA, Ana Paula. "Relações étnico/raciais e de gênero na escola e no espaço acadêmico: experiências de jovens negras da Universidade de Brasília". Revista Educação, UFSM, jan./abr. 2009. Dossiê Antropologia \& Educação. No prelo.

YOUNG, Iris Marion. "Representação política, identidade e minorias". Lua Nova, São Paulo, n. 67, p. 139-190, 2006.

[Recebido em novembro de 2008

e aceito para publicação em dezembro de 2008] 


\section{Afirmative Action in the Educational System: Trajectories of Young Black Women at the University of Brasilia}

Abstract: This article presents the experiences of black female students admitted by the University of Brasilia through the affirmative action programme. They attend courses in Engineering and Social Sciences and have experienced different school socialization processes. By choosing students of different academic courses and school backgrounds we tried to analyse their experiences with racism and prejudice and also the strategies to overcome these situations. $A$ second focus of our analyses lies on the experiences of black female students and their attitude toward affirmative action in public universities of Brazil. We agreed that it is not sufficient to say that this policies are fair because they are in accordance to the imperative of social justice, if the results are not evident. The establishment of systems of quotas is not the only way of recognition and redistribution, but it reflects the necessity of an adjustment of the university system to the political and social requirements of the Brazilian society and its people.

Key Word: Affirmative Action; University; Blacks and Education; Youth; Gender. 